\title{
Opportunities and Challenges for Social Security Work in a Big Data Environment
}

\author{
Yu Zhou and Bei Ye \\ Wuhan University of Science and Technology, Wuhan, Hubei, China
}

\begin{abstract}
With the rapid development of the era of big data, the information road of social security has been accelerating. In China, social security is a vast livelihood problem and a huge and complex system. The powerful analytical and data processing capabilities of large data are just conducive to solving the problem of social security work with huge data. This paper mainly uses the literature research method to focus on the opportunities and challenges brought by big data to social security, and explore the development direction of social security in China under the big data environment.
\end{abstract}

\section{Keywords-big data; social security; opportunity challenge}

\section{INTRODUCTION}

Today, with the rapid development of information technology, big data has become the standard configuration for various industries. Many industries use it for industry analysis, and infer industry development trends, and various industry problems. The use of big data has brought opportunities and accurate information to many industries. For social security work, big data also has its special value. The human society system produced a large amount of data and information during the various business processes, and they were closely related to the vital interests of the masses, forming the big data of human society. Social security big data consists of three parts: basic social security data, auxiliary social security data, and external data. From the perspective of information service needs and relying on social security big data, "Big Data + Social Security Information Service" can enable participants to accurately understand each social security policy and its own social security status; it can enable the government to provide openness, transparency, and efficiency Social security information services, and provide a reference for their own social security decisions; can effectively improve the social security related groups' practical ability and professional level. To provide or obtain social security information through the Internet's big data, providers need to screen, sort, sort, and organize information data. Users need to use data accurately and effectively through legal channels in accordance with laws and regulations. However, there are still problems such as a low level of overall planning, difficult transfers, and non-interoperability of information. At present, in the field of social insurance, the role of big data is increasingly prominent, but the data has not yet become a system, and it is lacking in data collation, analysis, processing, and utilization. In recent years, social insurance management has been mainly concentrated on the macro management level, but there are not many actuarial and refined management in the management of insurance personnel, financial management, and fund management. Big data is conducive to the improvement of social security management capabilities, service capabilities and handling capabilities.

\section{THE BIg DATA ENVIRONMENT BRINGS OPPORTUNITIES FOR SOCIAL SECURITY WORK}

\section{A. Reduced the Cost of Managing Stored Data}

China's social security policy has brought living security to the residents, so that our people are kept above the subsistence level. So social security has played a key role in my national life. However, due to the large population base in China, the huge social security data is difficult to manage before. It can only expand the storage and increase the server, and increase the manpower input.Therefore, both in terms of manpower and material resources, A lot of costs are wasted, and a lot of information makes it difficult to find them quickly when using them, and it also wastes unnecessary time. Whether it is data storage space, data management staff, and information management of huge databases, there are many problems to be solved. The emergence of big data has brought a ray of light to these problems, making the nationwide social security data network possible, and cloud storage solves the problem of huge data storage and calling, greatly reducing the cost of manpower and materials. Since the emergence of big data, it has become possible to centrally manage a large number of social security information. Using cloud storage technology, it can store a large amount of data, and can also centrally manage and analyze such data, reducing manpower and resources which improve the efficiency of social security.

\section{B. Social Security Information is Shared}

The network reduces the distance between time and space, making information sharing a simple matter. Big data and cloud storage technologies solve the problem of sharing such huge amounts of information as social security. With the advent of the era of big data, social security information can be shared across time and region, so that people in different places can enjoy the welfare of the country, share information through big data, and protect people's illness and medical treatment. Because of the universal use of social security information across the country, even if they are outside, they can still enjoy local social security, which truly protects people's lives, enables people to be protected in economic activities when they go out, and protects the fundamental interests of migrant workers. Through information sharing, social security information can be found in all parts of the country, and the pension system can 
be improved, so that people can feel the welfare policy of the country, improve people's living standards, improve living conditions, improve medical problems, and Good social security.

\section{Providing a Broader Platform for the Implementation of Social Security Work}

The arrival of the era of big data has broadened the platform for social security work. In terms of medical benefits, big data also provides a very convenient platform. People are more convenient when they seek medical treatment, reducing unnecessary waste of time. As long as there is a computer, they can query information and improve the efficiency of social security work. The platform of big data, while facilitating the medical staff, also facilitates the medical staff, can more easily understand the patient's medical treatment, help the patient to complete the consultation and medical treatment process very simply and efficiently, and alleviate the long queue and registration of the hospital. In the situation, the medical staff can understand the condition more quickly and make a new diagnosis. The patient can get a better understanding of the condition and take corresponding countermeasures according to the doctor's advice, which greatly facilitates the medical procedure. The application of big data optimizes the health insurance governance model. It includes: enriching the participants of medical insurance governance; enhancing the fairness of medical insurance, because the development of big data broadens the breadth and depth of information acquisition, effectively reducing the information inequality.

\section{The Big Data EnVIRONMENT BRINGS Challenges to SOCIAL SECURITY WORK}

\section{A. Network Information Security Aspects}

The network itself is a tool for people's information sharing. Its development speed and development ability are beyond our imagination. When people use big data to manage social security information, they must do a good job in the security protection of big data. Now that network information is so developed, many unscrupulous people use superb network technology to steal information and use various types of information to exchange interests. This phenomenon is very common. In order to prevent this phenomenon, we must do a good job Security. People's social security information is usually effective and privacy-related information. It is a very useful business opportunity for merchants and a profitable tool for criminals, but for individuals, their information should never and cannot be Used by others for profit. Social security information includes information about social groups such as enterprises, government policies, personal privacy, and its importance is self-evident. It involves the interests of all levels of society. The use of big data to manage social security information requires information about big data. Encryption protection effectively protects the security of big data. If the information is improperly protected or leaked, the consequences are unimaginable. In the context of big data, there have been too many problems of trafficking information and information leakage. Such problems must not occur in the social security system. While big data brings convenience to social security information, it also brings challenges to the security of social security work. In the information age, we must pay attention to these interests, take good anti-theft measures, avoid the loss or misappropriation of social security information, and back up. Therefore, before using big data technology, adequate precautions should be taken to ensure that the entire social security system is foolproof.

\section{B. Utilization of Social Security Staff}

With the advent of the era of big data, new requirements have also been set for the quality of social security staff. They are required to be able to adapt to the ever-evolving technical needs, use new technology and technology in daily work, and improve efficiency. The types of big data are complex, systems are cumbersome, and different aspects of technology require talent. If the social security staff does not have good professional ethics and the correct three perspectives that serve people, the problem of leakage of social security information will also occur. Take a variety of measures and channels to cultivate talents that meet the requirements of the times, and expand the skilled talents that meet the new era. It is also necessary to protect the moral quality of the staff, establish correct values, do not do things that endanger the interests of the people and society, and adhere to the purpose of serving the people. We must pay attention to the training of staff informatization skills, improve their skills and qualities to adapt to the information warfare of modern society, and cultivate dual talents who are proficient in operating computers and handling social security operations, so that staff members realize that The importance of improving national social security. Create a good working environment for social security staff, let them keep up with the times to learn computer technology, master the core theory of big data, and use the advantages of big data to process social security work, improve work efficiency, and use technical talents Role in the era of big data. So for social security staff, they should manage and inspect their ideology, morals and morals, restrain their behavior and promote positive energy. At the same time, the improvement of work technology requirements is also conducive to the selection of staff quality.

\section{The Solution Strategy for Big Data Problems}

\section{A. Social Security Staff Management}

The professional ability and professionalism of social security workers should be improved, and their social security policies and big data use skills should be trained to have logical analysis ability, predictive ability, data search ability, computer skills and related software application operation capabilities. The business must be proficient in, and regular training of professionalism, so that it has a good professionalism and ethical standards, with the spirit of serving the people and noble morality.

\section{B. Formulating Control Laws and Punitive Measures}

The registration process, use process and storage of social security data should be strictly supervised, relevant laws should be formulated, severe punishment measures should be taken against those who leak information, and people's social security information should be protected from violations by compulsory means. Institutional construction to promote the development 
of social security data. Top-level design at the national level, taking social security information big data construction as a national key task, setting up social security big data management institutions, formulating social security big data research and development plans, and focusing on improving the government's management capabilities in social security; Accelerate the construction of backbone networks and data centers at the national, provincial, city, and county levels, build an information network covering the entire country, and connect urban and rural areas, and realize network connectivity; use nationally standardized social security information data codes to strengthen social security information systems between regions The network enables various social security data to be uploaded accurately and in real time, ensuring the authenticity and integrity of the uploaded data. At the same time, formulate standards and rules for data collection and management, determine the procedures, scope, and responsibilities of data use and openness, and ensure that personal privacy is not violated and social security data is safe.

\section{THE CONCLUSION}

The report of the Nineteenth National Congress also pointed out that it is necessary to accelerate the deep integration of big data and the real economy, accelerate scientific and technological innovation, and build a digital China. The era of big data is the fruit of the development of modern science and technology, and it is produced in an informatization that fits the lives of modern people. The opportunities it brings to our social security work, we must make good use of it, give full play to the advantages of big data, strengthen the centralized management of social security information, effectively protect the security of social security information, allow social security information to be shared in a standardized manner, and let people across the country Both can enjoy the state's welfare policy and improve and improve people's living standards. At the same time, we must also respond to the challenges brought by the era of big data. Strengthen the information quality of social security staff, cultivate their sense of responsibility, and strengthen their skills training so that they can operate computers proficiently and at the same time be proficient in social security operations. The two are combined into one, and for the social security cause in China through big data make a contribution. In particular, we must pay more attention to security issues. The protection of social security information must not be ignored, the moral quality of relevant personnel must be guaranteed, and there must be a minimum moral bottom line. This will improve the country's social security, promote people's progress in life, and build a better motherland.

In the era of big data, social security work with a huge population base has not only increased efficiency with the support of big data technology, but also faces the risk of information leakage under the premise of information sharing. Among the opportunities and risks, social security work must not only seize opportunities, but also face difficulties and solve problems. In terms of opportunities, the use of cloud storage, data mining, data analysis and other technologies has enabled data to be well-preserved and applied, established a shared network to provide convenient and efficient services for people's lives, established an online pre-diagnosis platform on medical issues, etc. A series of advantages. In terms of issues, it is more a problem of information leakage, and the consequences of information leakage by social security personnel are unimaginable. In order to solve this problem, the first solution is to ensure security when using big data platforms for information storage and sharing. In general, the use of big data outweighs the disadvantages, but the problem of data security must not be ignored. The problem is not resolved, and big data technology cannot be fully popularized in social security work.

\section{ACKNOWLEDGMENT}

Thanks to researchers cited in this paper. And comments are welcome and appreciated.

\section{REFERENCES}

[1] Guo Shiying, Bai Weijun. The Generation Logic and Implementation Path of the Demand of "Internet + Social Security Information Service" [J]. Administrative Forum, 2019, 26 (04): 140-144.

[2] Bai Zengqiu. On the Application of Information Technology in Social Security File Management [J]. Office Business, 2019 (07): 47.

[3] Yang Wei. Research on the innovation of Shanghai Social Security Service Mode under the background of "Internet +" [D]. Shanghai Normal University, 2018

[4] Yu Fengyuan. Research on the problem and countermeasures of medical insurance fraud based on big data [D]. Shandong University of Finance and Economics, 2018.

[5] Zhang Teng. The investment management mode of social security funds and the way to get rid of difficulties in the context of big data era $[\mathrm{J}]$. China's strategic emerging industries, 2018 (24): 211.

[6] Hao Tian. Research on Social Security Information System Management in the Age of Big Data[J]. China Strategic Emerging Industries, 2018(20): 128.

[7] Wang Shouping. Reflections on the application of big data analysis and analysis of social insurance in Shandong Province [J]. Shandong Human Resources and Social Security, 2018 (Z1): 51-53. 